\title{
Evaluation of factors affecting students' performance in tertiary education
}

\author{
Kawtar Tani ${ }^{1}$, Elizabeth Dalzell2 ${ }^{2}$ Nathan Ehambaranathan ${ }^{3}$, Sheela Murugasu ${ }^{4}$ and Anne Steele ${ }^{5}$ \\ 1 Universal College of Learning, School of Business and ICT, New Zealand (ORCID: 0000-0003-1031-9536) \\ 2Universal College of Learning, School of Business and ICT, New Zealand (ORCID: 0000-0003-1150-5883) \\ ${ }^{3}$ Universal College of Learning, School of Business and ICT, New Zealand (ORCID: 0000-0002-6485-6882) \\ ${ }^{4}$ Universal College of Learning, School of Business and ICT, New Zealand (ORCID: 0000-0001-8915-5444) \\ ${ }^{5}$ Universal College of Learning, School of Business and ICT, New Zealand (ORCID: 0000-0003-1728-3425)
}

\begin{abstract}
The aim of this study is to evaluate factors contributing to poor academic performance of students in higher education. Data was collected in 2017 from 216 students enrolled in different programmes at a higher education provider in New Zealand. The effect of factors relating to family obligations, work and social commitments, and financial concerns were analysed. Results showed significant relationship between academic performance of students and their attendance. Other significant findings included the relationship between attendance and the level of study; work shift; ethnicity; whether participants had any dependents; and how studies were funded. Implications and limitations of this study are presented.
\end{abstract}

Keywords: Class performance; Class attendance; Grade point average; Higher education

Article History: Submitted 21 December 2018; Revised 2 April 2019; Published online 23 May 2019

\section{Introduction}

Student class attendance is a major concern for higher education institutions. In today's learning environment, traditional methods of learning are continually being complemented by innovative teaching methods such as blended delivery and the use of online tools. The use of information technology means that students no longer have to sit through lectures to get course information, but through web-based approaches, information can be obtained at the click of a mouse. Indeed, the requirement to be in class has shifted from compulsory to voluntary for most courses, as long as the student is using the available tools to keep up to date with the course content and maintains good academic performance. Absenteeism, as Landin and Perez posit, "should be related to the lack of compulsory attendance and the possibility of passing the course without any requirement of attendance" (2015, p. 80). It has, however, been shown that absenteeism affects students' academic performance. Landin and Perez (2015), for example, reported a significant relationship between students' attendance and their grades, where students who attended all lectures gained significantly higher grades than those who did not attend all the lectures. Similarly, other studies agreed that students who attend classes are better performers academically compared to those who miss classes (Aden, Yahye, \& Dahir, 2013; Andrietti, 2014; Dobkin \& Marion, 2010; Latif, \&

Address of Corresponding Author

Kawtar Tani, Universal College of Learning, School of Business and ICT, Private Bag 11022, Palmerston North 4442, New Zealand.

$\triangle$ k.tani@ucol.ac.nz

How to cite: Tani, K., Dalzell, E., Ehambaranathan, N., Murugasu, S., \& Steele, A. (2019). Evaluation of external factors affecting students' academic performance in higher education in New Zealand. Journal of Pedagogical Research, 3(2), 1-10. 
Miles, 2013), notwithstanding that a few absences do not lead to poor grades, but excessive absenteeism does (AbuRuz, 2015).

Cheruvalath (2017) stated frequent class attendance allows students to develop their understanding and interacting skills towards their peers in various adaptive manners. The research findings indicated at least $40 \%$ of college students with good class attendance are likely to gain and endorse human values in comparison to students attending fewer classes. Students tend to have low class attendance and poor performance when they are experiencing housing instability which ultimately leads to their tendency to discontinue their enrolled courses at the university (Silva et al., 2015). Rubin and Wright (2015) identified that working-class students tend to have less social integration, which leads to poor performance and class attendance due to their additional commitments. These students are likely to have more responsibilities such as work and childcare which prevent them from attending classes and events at the university.

Institutions that are outcome-based perceive academic failure as students not passing their courses. However, other perspectives posit that academic failure is when students perform below their potential. Consensus exists amongst the different studies that focused on investigating factors that affect student achievement, and reported a positive relationship between socio-economic, psychological, and environmental factors and academic performance. Among these factors most reported are motivation (Komarraju, Karau, Schmeck, \& Avdic, 2011); student's attitude (Mushtaq, \& Khan, 2012); prior academic achievement (Diseth, 2011); parents' education level (Mushtaq, \& Khan, 2012); personality traits (Feldman, Chandrashekar, S. \& Wong, 2016); age (Ali, Haider, Munir, Khan, \& Ahmed, 2013); ethnicity (Woolf, Potts, \& McManus, 2011); and gender (Zacherman, \& Foubert, 2014).

Other factors that have also been identified as factors contributing to poor academic performance, but are under-reported include social commitments (Lee \& Shute, 2010); and financial concerns (Darolia, 2014). Indeed, student well-being is considered a crucial impediment to academic success (Kutsyuruba, Klinger, \& Hussain, 2015). A few studies were conducted to investigate the relationship between student well-being and intent to drop out, and found that students who reported high stress levels, more fatigue, and those who did not live in the vicinity of the institution were more likely to indicate their intent to drop-out (Hughes \& Smail, 2015).

In exploring the relationship between student attendance and exam performance, some of the major reasons given by students for not attending classes included poor delivery of lecture, timing of lectures, assessment pressures, and work commitments (MIambo, 2011). It has also been reported that the need to seek employment while studying, and the number of part-time and mature students has risen in recent years (MIambo, 2011). Consequently, students may be expected to fulfil obligations to the family that conflict with college responsibilities (Espinoza, 2010). Indeed, mature and part-time students were reported to have higher attrition rates, typically due to problems associated with finance, family or work commitments (Grebennikov, \& Shah, 2012; Schofield, \& Dismore, 2010).

The purpose of the present study was to explore the effect of external factors on students' academic performance in higher education.

\section{Method}

\subsection{Participants}

The sample consisted of 216 students (109 males and 107 females) at a higher education provider in New Zealand. Participants were students at different course levels; Level 3 (17), Level 4 (25), Level 5 (67), Level 6 (55), and Level 7 (52). A listing of the various programmes, levels and corresponding number of students surveyed is presented in Table 1.

Of these students, 34 were international students and 182 were domestic (from within New Zealand) students. The mean age of students was 26.97years $(S D=8.40)$. Participants identified themselves as European (104), Asian (54), Maori (44), Pasifika (4), and other ethnicity (8) not specified by participants. 
Table 1.

Course details and number of students per programme

\begin{tabular}{|c|c|c|c|}
\hline Programme & Course Level* & $\begin{array}{c}\text { Number of students on } \\
\text { each level }\end{array}$ & Total \\
\hline \multirow[b]{2}{*}{ Computing } & Level 6 & 36 & \multirow[b]{2}{*}{61} \\
\hline & Level 7 & 25 & \\
\hline Trades Training & Level 3 & 17 & 17 \\
\hline \multirow{4}{*}{ Business } & Level 4 & 14 & \multirow{4}{*}{46} \\
\hline & Level 5 & 17 & \\
\hline & Level 6 & 12 & \\
\hline & Level 7 & 3 & \\
\hline Beauty & Level 4 & 11 & 11 \\
\hline Hospitality & Level 5 & 21 & 21 \\
\hline \multirow{3}{*}{ Exercise and Sports } & Level 5 & 8 & \multirow{3}{*}{17} \\
\hline & Level 6 & 7 & \\
\hline & Level 7 & 2 & \\
\hline \multirow{2}{*}{ Nursing } & Level 5 & 21 & \multirow{2}{*}{43} \\
\hline & Level 7 & 22 & \\
\hline
\end{tabular}

*Levels 5, 6, and 7 are equal to the first, second and third levels of a degree programme. Level 3 and 4 are certificate levels.

\subsection{Instrumentation}

DaZealand andstudy was of students enrolled full-time on 8 programmes at a higher education provider in New Zealand, and was collected using a questionnaire that was given to students at the beginning of selected classes within a higher education institution in New Zealand. The selected courses aimed at different student groups, thereby making it possible to address many students from different levels and disciplines. Completing the two page-questionnaire took approximately five minutes.

The questionnaire dealt mainly with the determinants of academic performance, as reported by current literature. These were family obligations, work and social commitments, and financial concerns. To ensure students' anonymity, no identifiable data was recorded (e.g. names, contact details). Approval to conduct the study was obtained through the research ethics committee at the institution in which the research was conducted.

\subsection{Procedure}

Data was collected in 2017, using a questionnaire administrated by lecturers of the 8 programmes covered in this study during lecture and tutorial sessions during the last two weeks of semester 2, 2017. All questionnaires were accompanied by an information and consent cover letter, in which the aim of the study was explained, as well as that participation in the study was voluntary and that participants' anonymity was guaranteed. Students were asked to indicate whether they agree or disagree to participate in the study by ticking the appropriate option on the information and consent cover letter. 216 questionnaires were returned completed (response rate of 91\%).

For the purposes of data analysis, students' identification number and/or names were collected on the questionnaires. This allowed the collection of the age of the student, gender, ethnicity, enrolment type, attendance data, and Grade Point Average (GPA) from the institution's student database.

Academic performance was defined as the GPA in programmes at the end of the students' level of study. As a general measure of academic performance, the grades of participants at the end of semester 2, 2017, were used to compute an overall GPA for 2017.

Multiple regression analyses where GPA and attendance were the dependent variables, to examine relationships with the following variables: programme of study (name of programme), 
level of study (ranging from level 3 to level 7), working status (Yes/No), number of hours worked per week, shift worked (morning/afternoon/all day/night), accommodation status (Living at home with family/Flatting with students from the same institution/Flatting with students not at the same institution/Living alone/Boarding/Hostel/Other), number of people living with, mode of transport to the institution (Drive/Walk/Bus/Cycle/Other), distance from institution, any dependents (Yes/No), number of these dependents, funding type (StudyLink/Family Support/Self-funding/Grant/Other), enrolment type (Domestic/International), gender (Male/Female), ethnicity (European, NZ Maori, Asian, Pacifika, Other), and age.

Data were analysed using SPSS version 22.

\section{Results}

A linear multiple regression model with students' GPA as the dependent variable was statistically significant, $R^{2}=.17, F(8,192)=5.05, p<.05$. Average attendance and whether students had any dependents had significant positive regression on GPA, indicating that students with higher attendance $(\beta=.15, p<.05)$ and those with dependents $(\beta=.37, p<.05)$ were expected to have higher GPA. Distance from institution, working status, gender, level of study, enrolment type, and age were not statistically significant in this model.

There was a significant effect of the programme of study on GPA at the $\mathrm{p}<.05$ level $(F(6,209)=6.88, p<.001)$. Post hoc analyses (Tukey HSD) revealed the following pairs wise comparisons to be significantly different $(p<.05)$ : Computing and Business $(p=.018)$, Computing and Hospitality $(p=.009)$, Business and Trades $(p=.007)$, Business and Nursing $(p=.049)$, Business and Beauty $(p=.014)$, Business and Hospitality $(p=.000)$, Nursing and Hospitality $(p=$ .013). Group means for GPA per programme may be viewed in Table 2. Work shift, funding type, and ethnicity were not statistically significant in this model.

Table 2.

Group means for GPA by programme

\begin{tabular}{lccc}
\hline & Mean & Std. Deviation & $n$ \\
\hline Computing & 74.30 & 11.628 & 61 \\
Business & 66.28 & 17.932 & 46 \\
Trades & 78.94 & 10.152 & 17 \\
Sport & 73.65 & 10.464 & 43 \\
Nursing & 74.09 & 8.571 & 11 \\
Beauty & 80.36 & 8.016 & 21 \\
Hospitality & 85.29 & 10.095 & 216 \\
\hline Total & 74.24 & 13.298 & \\
\hline
\end{tabular}

A multiple regression model with students' average attendance as the dependent variable was also statistically significant, $R^{2}=.20, F(8,192)=5.94, p<.05$. The level of study, enrolment type, and GPA had significant positive regression average attendance, indicating that students enrolled in higher levels of study $(\beta=.14, p<.05)$, international students $(\beta=.14, p<.05)$, and those with higher GPA $(\beta=.36, p<.05)$ were expected to have higher average attendance. Distance from institution, working status, gender, dependents, and age were not statistically significant in this model.

Analysis of variance was used to investigate the effect of four further variables that were not suitable for inclusion in the regression analyses (i.e., programme of study, work shift, funding type, and ethnicity). There was a significant effect of the programme of study on average attendance at the $p<.05$ level $(F(6,202)=5.83, p<.001)$. Post hoc comparisons (Tukey HSD) revealed the following pairs wise comparisons to be significantly different $(p<.05)$ : Computing and Business $(p=.010)$, Computing and Sport $(p=.000)$, Trades and Sport $(p=.009)$, Sport and Nursing $(p=.000)$, and Sport and Hospitality $(p=.002)$. Group means for average attendance by programme may be viewed in Table 3 . 
Table 3.

Group means for average attendance by programme

\begin{tabular}{lccc}
\hline & Mean & Std. Deviation & $n$ \\
\hline Computing & 86.97 & 13.88 & 59 \\
Business & 77.82 & 17.17 & 45 \\
Trades & 84.76 & 10.15 & 17 \\
Sport & 67.75 & 15.12 & 16 \\
Nursing & 85.36 & 11.75 & 42 \\
Beauty & 77.00 & 12.98 & 11 \\
Hospitality & 86.11 & 10.10 & 19 \\
\hline Total & 84.42 & 14.72 & 209 \\
\hline
\end{tabular}

There was a significant effect of the work shift on average attendance at the $p<.05$ level $(\mathrm{F}(4,110)=2.71, p=.034)$. Post hoc comparisons using the Tukey HSD tests were conducted on all possible pairwise contrasts, and found that Afternoon shift and Night shift were significantly different $(p=.034)$. Group means for average attendance per shift type may be viewed in Table 4 .

Table 4.

Group means for average attendance by shift

\begin{tabular}{lccc}
\hline & Mean & Std. Deviation & $n$ \\
\hline Morning & 82.56 & 15.15 & 43 \\
Afternoon & 79.52 & 15.71 & 33 \\
All day & 77.78 & 15.52 & 9 \\
Night & 90.70 & 8.95 & 23 \\
Other & 87.60 & 17.97 & 10 \\
\hline Total & 83.36 & 15 & 118 \\
\hline
\end{tabular}

Note: only those who work were entered into this analysis.

There was a significant effect of the funding type on average attendance at the $p<.05$ level $(F(4,200)=3.38, p=.011)$. Post hoc comparisons using the Tukey HSD tests were conducted on all possible pairwise contrasts, and found that Funding through StudyLink and Other type of funding were significantly different $(p=.018)$. Group means for average attendance per funding type may be viewed in Table 5 .

Table 5.

Group means for average attendance by funding

\begin{tabular}{lccc}
\hline & Mean & Std. Deviation & $n$ \\
\hline StudyLink & 80.40 & 14.87 & 142 \\
Family Support & 86.76 & 13.87 & 34 \\
Self-funding & 83.42 & 15.02 & 12 \\
Grant/Scholarship & 79.14 & 14.38 & 7 \\
Other & 93.14 & 8.32 & 14 \\
\hline Total & 82.42 & 14.72 & 209 \\
\hline
\end{tabular}

There was a significant effect of ethnicity on average attendance at the $p<.05$ level $(F(4,200)=4.34, p=.002)$. Post hoc comparisons using the Tukey HSD tests were conducted on all possible pairwise contrasts. The following pairs of groups were found to be significantly different $(p<.05)$ : European and Asian $(p=.012)$, Maori and Asian $(p=.001)$ were significantly different. Group means for average attendance per ethnicity type may be viewed in Table 6. 
Table 6

Group means for average attendance by ethnicity

\begin{tabular}{lccc}
\hline & Mean & Std. Deviation & $n$ \\
\hline European & 80.89 & 14.67 & 103 \\
Maori & 77.29 & 15.73 & 41 \\
Asian & 89.06 & 12.31 & 51 \\
Pasfika & 85.80 & 7.29 & 5 \\
Other & 83.78 & 14.90 & 9 \\
\hline Total & 82.42 & 14.72 & 209 \\
\hline
\end{tabular}

\section{Discussion}

Not all of the independent variables used in this study explained the variation in grades of participants. Of those that were significant were the attendance variable, whether participants had any dependent, and the programme of study.

A key finding of this study is the effect of class attendance on students' academic performances. The class attendance variable was significant indicating that the higher the students' attendances, the better students' grades. This finding aligns with previous study findings where a similar effect was found (Aden, Yahye, \& Dahir, 2013; Andrietti, 2014; Latif, \& Miles, 2013). Furthermore, this study also found that GPA had an effect on student attendance. There was strong evidence that students with higher GPA tended to have a higher attendance rate. This two-way effect between GPA and attendance is not surprising given the extant literature supporting the positive relationship between these variables (MIambo, 2011).

Students' GPA differed significantly according to the programme of their studies. The results showed that students enrolled in the hospitality programmes tended to have higher GPA. These students also appeared to have a high attendance rate of the programmes under study, which is not surprising given the relationship between attendance and GPA that we found. Similarly, students enrolled in the sport programme had the lowest attendance rate and a low GPA. However, results also showed that higher attendance did not always mean higher GPA, as found for students enrolled in the computing programme. The latter had a high rate of attendance, but not necessarily a high GPA. This could be due to a number of reasons: some programmes might be more complex in nature, in that some might require understanding of complex theories, and some might require more hands-on work that require compulsory attendance. Also, entry requirements to programmes is different in that some programmes require prior learning and qualifications in the field, while some at a lower level do not have any specified pre-requisites. Hamamci and Hamamci (2017) posited that the differences among the natures of the subjects and class sizes may account for differing results in the relationships between absenteeism and grades. It may also be that the different types of examination on each programme could have an effect on the final scores of students. For example, scores on exams may be affected by failure to attend classes, by may not have an effect on student learning. Another possible explanation could be that the level of effort required by students to complete their studies may differ by programme.

Although only few studies have found minor association between students' attendance and their scores (e.g. AbuRuz, 2015), a large number of empirical studies acknowledge the positive relationship between attending classes and academic performance, which we support in this study.

When students were asked whether they had any dependents, those who indicated that they had a dependent were more likely to have a higher GPA than those who did not have a dependent. There was no significant effect of dependents on attendance, as such those who had dependents appeared to do well academically, regardless of their average attendance. It could be that having someone to care for while studying is a motivating factor to do well and improve one's employment prospects. Indeed, Espinoza (2010) posited that family obligations such as supporting 
a family and children can complicate the student's experience in higher education. The implication of family obligations warrant further research in order to draw conclusions on its effect on academic performance.

In the country where this study was conducted, there is a requirement for international students to achieve over $95 \%$ attendance in order to maintain a student visa, it was therefore expected to find the rate of attendance of international students higher than domestic students. The consequences of missing classes are far more serious than just not achieving high scores. For international students, it is the difference between successfully renewing a student visa and being able to complete the programme of study, and being refused to continue in the programme with a possibility of being asked to go back home. No significant relationship was found between the GPA and enrolment type, no statements can therefore be made about the relationship between the high attendance of international students and their GPA.

There was a significant effect of ethnicity on average attendance. Asian students appeared to attend classes more than European and Maori students, with Maori students' attendance being the lowest of all groups explored in this study. This finding is closely related to the significant effect found between the type of enrolment and class attendance. Most Asian students would be international students whose attendance is compulsory as discussed earlier, while European and Maori students are likely to be domestic students, whose attendance is not compulsory.

The Ministry of Education (2016) reported a national decrease in student attendance, where Asian students had the highest rates of regular attendance in 2016, at 77\%, European students followed at 70.5\%, Pasifika students at 57.2\%, and Maori students reported the lowest attendance rates, with only $54.7 \%$ of students regularly attending school (Ministry of Education, 2016). In 2017, a similar survey reported that students who identified as Māori and Pasifika had lower rates of regular attendance than other ethnicities (50\% and $52 \%$, respectively). According to the 2017 survey, the latter spent more than twice as long away from class for unjustified reasons than students of other ethnicities (Ministry of Education, 2016). Meissel and Rubie-Davies (2015) investigated the goal orientation and self-efficacy beliefs among students of different cultural backgrounds in New Zealand. Their findings revealed that there are differences among the motivation levels within the Mãori and Pasifika students as they are more likely to be affected by their self-efficacy compared to other students.

In our study, perhaps a more interesting finding is the difference between attendance of European students and Maori students. The 'unjustified reasons' for missing class as reported by the Ministry of Education Report (2017) alludes to the need to further investigate factors influencing some ethnicities' attendance. One plausible factor could be the difference in culture (Schmulian \& Coetzee, 2011). The authors reported that culture and ethnicity may have an effect on the relationship between class attendance and academic performance. In our study however, no significant relationship was found between the GPA and ethnicity, no statements can therefore be made about the relationship between the low attendance of Maori students and their GPA.

The findings suggest that students enrolled in higher levels of study attend classes more than those at lower levels. This finding can be attributed to the structure of programmes from a beginner level to an advanced level, where the advanced level is a stage where more focus and efforts are required. Attending classes and having the opportunity to interact with the lecturer at higher levels might be a way of ensuring that the more complex expectations of advanced courses will be met. According to Taylor et al (2017), higher institutions should focus on organising engagement activities particularly among the first year students to encourage the establishment of good attendance habits at the outset of their studies.

Amongst those who worked, there was a significant effect of the work shift on average attendance where attendance of students working night shifts was higher than those who worked afternoon shifts. This finding was predictable given that courses in the institution where the study was conducted were day courses. Working a night shift means that the student was able to attend courses during the day. 
Our results showed a significant effect of the funding type on average attendance, where students funding their studies through bank loans, or those funded by their employers, were more likely to attend classes than those funding their studies through StudyLink. The frequent class attendance of these students could be an indication that these students appear to take their education more seriously, and know the value of money more than students funded by StudyLink. A similar effect was discussed by Darolia (2014) where students who supported themselves through work and/or loans were more likely to attend classes on regular basis. Indeed, a student funding their studies through StudyLink does not have to pay the funds back until completion of their programme, and only if they are earning above the repayment threshold set by the government. Whereas a student funding their studies through a bank loan will have to start paying the bank back immediately after withdrawing the funds, and regardless of their employment status. Similarly, a student who is work-funded is obliged to succeed in their studies otherwise they run the risk of paying the funds back to their employer, or worse, losing their job and having the funds deducted from their final salary.

\section{Conclusion}

The effect of absenteeism on student performance has been a major topic for most educational institutions. Although class attendance does not guarantee success, it can enhance the probability of academic success. Based on previous performance of students, those whose previous GPA are known to be low, for example fall below the median, can be targeted and encouraged to attend classes in order to achieve better grades in their future courses. In saying that, it is also important to mention that there may be other factors influencing attendance and GPA of students, as found for our Maori student population. These findings underline the complexity of the students' educational environment, where simply making attendance compulsory, standardising the structure of programmes, or restricting funding for studies so that students know the value of money may not lead to better academic performance by implication. Instead, a variety of academic, non-academic and personal factors such as the challenges faced by students should be taken into account when analysing the factors that may affect attendance and student performance in higher education.

\subsection{Limitations}

A potential limitation associated with this study is that it was conducted at a single, small higher education institution with a limited number of students enrolled in different programmes at different levels. As a result, care should be taken in generalising the results to other institutions. In addition, the factors influencing academic performance and attendance reported in this study could vary between academic environments and cultural settings, all of which would limit the generalisation of our findings.

With regards to participants funding their studies though StudyLink, our study did not differentiate between students receiving a study loan to cover their fees only, and those receiving a study loan and an allowance to cover their living expenses.

Lastly, our study did not differentiate between morning and afternoon courses, it could be that students' attendance in these courses varies depending on what shift they are working. In our study, we found that students working night shift were attending courses more than students working afternoon shifts. It would be interesting to investigate what courses these students were attending. It can be speculated that students working night shifts will be more likely to attend afternoon courses.

\subsection{Suggestion for Further Research}

Future studies investigating significant factors in affecting academic success are warranted. Quantitative research should be done with a larger more representative sample of students across a number of higher education institutions, to get a better understanding of the effect of external factors on student engagement and success in academia. These external factors can be analysed 
and compared by other variables such as ethnicity, age and gender to demonstrate how differences may vary amongst students in different academic settings.

\section{Disclaimer}

This study is the result of the research carried out by researchers within the Business School, at the Universal College of Learning, New Zealand.

\section{References}

AbuRuz, M. E. (2015). Does excessive absence from class lead to lower levels of academic achievement? European Scientific Journal, ESJ, 11(7).

Aden, A. A., Yahye, Z. A., \& Dahir, A. M. (2013). The effect of student's attendance on academic performance: a case study at simad university mogadishu. Academic Research International, 4(6), 409.

Ali, S., Haider, Z., Munir, F., Khan, H., \& Ahmed, A. (2013). Factors contributing to the students academic performance: A case study of Islamia University Sub-Campus. American journal of educational research, 1(8), 283-289.

Andrietti, V. (2014). Does lecture attendance affect academic performance? Panel data evidence for introductory macroeconomics. International Review of Economics Education, Volume 15, January 2014, Pages 1-16

Cheruvalath, R. (2017). Does attending classes help foster human values in college students? Active Learning in Higher Education, 18(2), 143-155.

Darolia, R. (2014). Working (and studying) day and night: Heterogeneous effects of working on the academic performance of full-time and part-time students. Economics of Education Review, 38, 38-50.

Dobkin, C., Gil, R., \& Marion, J. (2010). Skipping class in college and exam performance: Evidence from a regression discontinuity classroom experiment. Economics of Education Review 29(4), 566-575.

Diseth, Å. (2011). Self-efficacy, goal orientations and learning strategies as mediators between preceding and subsequent academic achievement. Learning and Individual Differences, 21(2), 191-195.

Espinoza, R. (2010). The good daughter dilemma: Latinas managing family and school demands. Journal of Hispanic Higher Education, 9(4), 317-330.

Feldman, G., Chandrashekar, S. P., \& Wong, K. F. E. (2016). The freedom to excel: Belief in free will predicts better academic performance. Personality and Individual Differences, 90, 377-383.

Grebennikov, L., \& Shah, M. (2012). Investigating attrition trends in order to improve student retention. Quality Assurance in Education, 20(3), 223-236.

Hamamc1, Z., \& Hamamc1, E. (2017). Class attendance and student performance in an EFL class: is there a relationship? Journal of Educational \& Instructional Studies in the World, 7(2), 101-106.

Hughes, G., \& Smail, O. (2015). Which aspects of university life are most and least helpful in the transition to HE? A qualitative snapshot of student perceptions. Journal of Further and Higher Education, 39(4), 466-480.

Komarraju, M., Karau, S. J., Schmeck, R. R., \& Avdic, A. (2011). The Big Five personality traits, learning styles, and academic achievement. Personality and individual differences, 51(4), 472-477.

Kutsyuruba, B., Klinger, D. A., \& Hussain, A. (2015). Relationships among school climate, school safety, and student achievement and well-being: a review of the literature. Review of Education, 3(2), 103-135.

Landin, M., \& Perez, J. (2015). Class attendance and academic achievement of pharmacy students in a european university. Currents in Pharmacy Teaching and Learning, 7, 78-83.

Latif, E., \& Miles, S. (2013). Class attendance and academic performance: A panel data analysis. Economic Papers: A journal of applied economics and policy, 32(4), 470-476.

Lee, J., \& Shute, V. J. (2010). Personal and social-contextual factors in K-12 academic performance: An integrative perspective on student learning. Educational Psychologist, 45(3), 185-202.

Meissel, K., \& Rubie-Davies, C. M. (2015). Cultural invariance of goal orientation and self-efficacy in New Zealand: relations with achievement. British Journal of Educational Psychology, 86, 92-111.

Mlambo, V. (2011). An analysis of some factors affecting student academic performance in

an introductory biochemistry course at the University of the West Indies. Caribbean Teaching Scholar, 1(2), 7992. 
Ministry of Education. (2016). New Zealand schools attendance survey, 2016. Wellington, New Zealand. Retrieved from https://www.educationcounts.govt.nz/_data/assets/pdf_file/0003/181812/2016Attendance-in-New-Zealand-Schools.pdf

Ministry of Education. (2017). New Zealand schools attendance survey - Term 2, 2017 Results. Wellington, New Zealand.

Retrieved from https://www.educationcounts.govt.nz/_data/assets/pdf_file/0003/184629/NewZealand-Schools-Attendance-Survey-2017.pdf

Mushtaq, I., \& Khan, S. N. (2012). Factors affecting students' academic performance. Global journal of management and business research, 12(9).

Rubin, M., \& Wright, C. L. (2017). Time and money explain social class differences in students' social integration at university. Studies in Higher Education, 42(2).

Schmulian. A., \& Coetzee, S. (2011). Class absenteeism: reasons for non-attendance and the effect on academic performance. Accounting Research Journal, 24(2), 178-194.

Schofield, C., \& Dismore, H. (2010). Predictors of retention and achievement of higher education students within a further education context. Journal of Further and Higher Education, 34(2), 207-221.

Silva, M. R., Kleinert, W. L., Sheppard, A. V., Cantrell, K. A., Freeman-Coppadge, D. J., Tsoy, E., \& Pearrow, M. (2015). The relationship between food security, housing stability, and school performance among college students in an urban university. Journal of College Student Retention: Research, Theory \& Practice, 19(3), 284-299.

Taylor, L., Brogt, E., Cheer, U., Baird, N., Caldwell, J., \& Wilson, D. (2017). Ethnicity and engagement in firstyear New Zealand law programmes. Journal Higher Education Research \& Development, 36(5), 1047-1060.

Woolf, K., Potts, H. W., \& McManus, I. C. (2011). Ethnicity and academic performance in UK trained doctors and medical students: systematic review and meta-analysis. BMJ, 342, d901.

Zacherman, A., \& Foubert, J. (2014). The relationship between engagement in co-curricular activities and academic performance: Exploring gender differences. Journal of Student Affairs Research and Practice, 51(2), 157-169. 